\title{
Obesity paradox in group 1 pulmonary hypertension: analysis of the NIH-Pulmonary Hypertension registry
}

\author{
S Mazimba ${ }^{1}$, E Holland ${ }^{1}$, V Nagarajan ${ }^{2}$, AD Mihalek ${ }^{1}$, JLW Kennedy ${ }^{1}$, and KC Bilchick ${ }^{1}$ \\ ${ }^{1}$ Department of Medicine, University of Virginia, Charlottesville, VA, USA \\ ${ }^{2}$ Department of Medicine, University of Texas Medical Branch, Galveston, TX, USA
}

\section{Abstract}

Background-The 'obesity paradox' refers to the fact that obese patients have better outcomes than normal weight patients. This has been observed in multiple cardiovascular conditions, but evidence for obesity paradox in pulmonary hypertension $(\mathrm{PH})$ remains sparse.

Methods-We categorized 267 patients from the National Institute of Health-PH registry into five groups based on body mass index (BMI): underweight, normal weight, overweight, obese and morbidly obese. Mortality was compared in BMI groups using the $X^{2}$ statistic. Five-year probability of death using the $\mathrm{PH}$ connection (PHC) risk equation was calculated, and the model was compared with BMI groups using Cox proportional hazards regression and Kaplan-Meier (KM) survival curves.

Results-Patients had a median age of 39 years (interquartile range 30-50 years), a median BMI of $23.4 \mathrm{~kg} \mathrm{~m}^{-2}\left(21.0-26.8 \mathrm{~kg} \mathrm{~m}^{-2}\right)$ and an overall mortality at 5 years of $50.2 \%$. We found a Ushaped relationship between survival and 1-year mortality with the best 1-year survival in overweight patients. KM curves showed the best survival in the overweight, followed by obese and morbidly obese patients, and the worst survival in normal weight and underweight patients (logrank $P=0.0008$ ). In a Cox proportional hazards analysis, increasing BMI was a highly significant predictor of improved survival even after adjustment for the PHC risk equation with a hazard ratio for death of 0.921 per $\mathrm{kg} \mathrm{m}^{-2}$ (95\% confidence interval: $\left.0.886-0.954\right)(P<0.0001)$.

Conclusion-We observed that the best survival was in the overweight patients, making this more of an 'overweight paradox' than an 'obesity paradox'. This has implications for risk stratification and prognosis in group $1 \mathrm{PH}$ patients.

\section{Introduction}

Obesity is one of the leading cardiovascular (CV) risk factors associated with increased morbidity and mortality. ${ }^{1,2}$ Numerous studies have demonstrated obesity as an independent $\mathrm{CV}$ risk factor that contributes significantly to the development of heart failure (HF), coronary artery disease, disordered breathing, pulmonary hypertension $(\mathrm{PH})$ and overall survival. ${ }^{3-6}$ Despite this amplification of CV risk associated with obesity, there is an

Correspondence: Dr S Mazimba, Department of Medicine, Division of Cardiovascular Medicine, University of Virginia, PO Box 800158, Charlottesville, VA 22908-0158, USA. SM8SD@ @scmail.mcc.virginia.edu.

Conflicts of interest: The authors declare no conflict of interest. 
unexpected survival advantage of obese patients in comparison with their normal-to-low body mass index (BMI) counterparts if there is established CV disease (CVD) ${ }^{7,8}$ This surprising observation of attenuated CV mortality among obese and overweight patients has been referred to as the 'obesity paradox', and was first described by Horwich et al. ${ }^{9}$ in a cohort of HF patients. The phenomenon of the obesity paradox has since then been described in a wide range of chronic $\mathrm{CV}$ conditions including $\mathrm{PH}{ }^{10-14}$ The evidence for obesity paradox in $\mathrm{PH}$ is considerably sparse and its validity hotly debated, as evidenced by the numerous editorials on the topic. ${ }^{15-19}$ Furthermore, obesity paradox appears to be confined to certain subtypes of HF. Given the heterogeneity of PH conditions and the global epidemic of obesity, we sought to investigate the association of obesity and mortality in patients with group $1 \mathrm{PH}$ from the National Institute of Health (NIH)-PH registry.

\section{Materials and Methods}

The NIH established one of the first large registries of PPH patients (all idiopathic PAH, familial PAH and anorexigen-associated) with the specific aim of characterizing demographic, clinical and laboratory findings of patients at the time of diagnosis, as well as determining the natural history of the disease with medical interventions. The methodology and enrollment have previously been published including the risk equation for predicting 5year survival probability. ${ }^{20} \mathrm{We}$ used the publicly available de-identified registry data set to investigate the relationship of obesity and survival in group $1 \mathrm{PH}$ patients. ${ }^{21}$ This may be accessed at https://biolincc.nhlbi.nih.gov/studies/pphreg. Briefly, patients were enrolled into the registry from 32 medical centers throughout the United States. PH was defined as a mean pulmonary arterial pressure of $>25 \mathrm{~mm} \mathrm{Hg}$ at rest or $30 \mathrm{~mm} \mathrm{Hg}$ with exercise at the time of hemodynamic assessment with cardiac catheterization. Patients were included in the study after the following secondary causes of PH were excluded: PH within the first year of life, congenital abnormalities of the heart, lungs or diaphragm, pulmonary thromboembolic disease, sickle cell anemia, history of intravenous drug abuse, obstructive lung disease, interstitial lung disease, arterial hypoxemia, collagen vascular disease, parasitic disease affecting the lungs, pulmonary artery or valve stenosis, or pulmonary venous hypertension.

\section{Study design and outcomes}

To evaluate the relationship between obesity and the clinical outcomes in the NIH PH database, we analyzed patients who had the necessary invasive hemodynamic data to determine the pulmonary hypertension connection ( $\mathrm{PHC}$ ) risk equation (mean right atrial pressure, mean pulmonary artery pressure and cardiac index) and the clinical variables for the calculation of BMI. Patients were followed for 5 years, and time to death was reported within 5 years of enrollment. The 5-year probability of survival was calculated as a number between 0 and 1 using the PHC risk equation based on the mean pulmonary arterial pressure, mean right atrial pressure and cardiac index. The calculated PHC 5-year survival probability, BMI and pulmonary artery systolic pressure were then evaluated using a multivariable Cox proportional hazards model. 


\section{Body mass index}

BMI was calculated as weight in kilograms divided by the square of the height in meters. We defined the BMI strata according to the World Health Organization (WHO) and NIH guidelines, ${ }^{1,22}$ with underweight $\left(<18.5 \mathrm{~kg} \mathrm{~m}^{-2}\right)$, normal weight $\left(18.5-24.9 \mathrm{~kg} \mathrm{~m}^{-2}\right)$, overweight (25.0-29.9 $\mathrm{kg} \mathrm{m}^{-2}$ ), obese (30.0-34.9 $\mathrm{kg} \mathrm{m}^{-2}$ ) and morbidly obese ( $235.0 \mathrm{~kg}$ $\mathrm{m}^{-2}$ ). We also used tertiles of obesity to analyze the interaction of obesity and the probability of survival during the study period.

\section{Statistical analysis}

Statistical analysis was conducted using SAS 9.4 (SAS Institute, Cary, NC, USA). Analyses of categorical variables were conducted using the $\chi^{2}$ test. The $\chi^{2}$ and Fisher's exact tests were used to compare categorical variables. The Wilcoxon's rank-sum test was used to test for differences in continuous variables. Categorical variables are presented as frequencies with percentages, whereas continuous variables are described using medians and interquartile ranges (IQRs). Survival analysis and Kaplan-Meier plots are used to show differences in adverse events between groups with stratification based on key predictor variables. The log-rank test was used to compare differences between groups in this survival analysis. Multi-variable Cox proportional hazards regression and multivariable logistic regression were used to model associations of BMI categories with mortality during followup. An $a$-value of 0.05 was used for statistical significance.

\section{Results}

Among the 310 patients in the registry, 267 patients 18 years of age or older with complete data for determination of BMI were included in the analysis. The distribution of BMI is shown in Figure 1. This shows a normal distribution centered around $22 \mathrm{~kg} \mathrm{~m}^{-2}$. Five BMI groups were generated based on typically used cutoffs for BMI indicating underweight, normal, overweight, obese and morbidly obese. ${ }^{22}$ The number of patients in these five groups was 28, 141, 71, 19 and 8, respectively. Patient characteristics based on these categories for BMI are shown in Table 1. Age, gender and race were similar across quintiles. Except for cardiac index, for which patients in the lowest BMI group had a slightly higher cardiac index, all other hemodynamic parameters were similar across quartiles.

The differences in survival among these groups for death at 1, 3 and 5 years of follow-up are shown in Figure 2a. The overall rates of death (in the entire patient cohort) at 1, 3 and 5 years of follow-up were $29.2 \%, 46.0 \%$ and $50.2 \%$, respectively. As shown in the figure, the group with the lowest rate of death at all time points was the overweight group ( $P=0.009)$, and rates of death were also lower in obese and morbidly obese patients compared with patients having either normal weight or underweight patients based on BMI.

The relationship between 1-year mortality and BMI was U-shaped, as shown in Figure 2b. The U-shaped relationship for mortality still was present 3 and 5 years, but the greater death rates for the underweight and normal weight groups versus obese and morbidly obese patients became more apparent at these time points $(P=0.009)$. With respect to obese and morbidly obese patients, by 3 years, Figure 2 a shows that mortality in patients with BMI $>30$ 
$\mathrm{kg} \mathrm{m}^{-2}$ was clearly lower compared with patients having normal weight, and patients with BMI $>30 \mathrm{~kg} \mathrm{~m}^{-2}$ had lower mortality rates than patients with a normal weight at all time points (Figure 2a). It is remarkable that patients who were underweight by BMI had similar mortality rates at all time points compared with patients having a normal weight based on BMI.

Considering that mortality rates were similar in underweight and normal weight groups, and mortality rates were also similar between obese and morbidly obese groups, Kaplan-Meier survival curves were constructed with underweight and normal patients grouped together and with obese and morbidly obese patients grouped together in Figure 3. The survival curves show a clear separation of survival in the three groups. Survival is best at all time points in the overweight group, consistent with the U-shaped relationship between BMI and survival noted in Figure 2; however, survival was much worse in the normal weight/ underweight group versus the obese/morbidly obese group. Although normal weight and underweight patients are grouped together for clarity of presentation, there was very little difference in the survival curves between the underweight and normal weight groups when survival curves were plotted for all five groups, and the same held true for the obese and morbidly obese groups.

Although mortality was lowest for the overweight group during the first year, the differences in mortality between the overweight and obese/morbidly obese patients became less prominent with longer follow-up and were significantly lower than those in the normal weight and underweight groups. As a result, we constructed a Cox proportional hazards model for mortality based on the BMI as a continuous variable and adjustment for the PHC risk equation. BMI was a highly significant predictor of mortality even after adjustment for the PHC risk equation with a hazard ratio of $0.921 \mathrm{per} \mathrm{kg} \mathrm{m}^{-2}$ (95\% confidence interval: $0.886-0.954)(P<0.0001)$. Age $(P=0.82)$ or gender $(P=0.50)$ were not significant in the multivariable model with BMI and the PHC risk equation, and they did not alter the significance of BMI or the PHC risk equation for mortality in this model Furthermore, the $\chi^{2}$ value for BMI was about half that of the PHC risk equation, indicating that BMI has a strong influence on mortality even after adjustment for the PHC risk equation.

\section{Discussion}

The present study of the NIH primary PH database aimed to evaluate the association between BMI and survival probability among patients with group $1 \mathrm{PH}$. The main finding of our study was that higher BMI (overweight status) was independently associated with improved probability of survival during the 5-year follow-up of the study, thus highlighting the existence of the 'overweight paradox' in group $1 \mathrm{PH}$ patients. We also found that BMI had a curvilinear relationship with the probability of survival in patients with group $1 \mathrm{PH}$. There was a ' $\mathrm{U}$-shaped' relationship of BMI and the risk of mortality in this cohort of $\mathrm{PH}$ patients even after adjustment for the PHC, age and gender. Mortality rates even in obese and morbidly obese patients were lower compared with both normal weight patients and underweight patients, but these patients had a higher mortality than patients in the overweight category. 
These findings mirror previously published studies in HF with respect to BMI and mortality. ${ }^{23-25}$ Cardiac cachexia, an important indicator of CV frailty, is characterized by a declining overall function that may serve as a surrogate maker for advanced disease status and therefore explain the observed increased mortality relative to the overweight/obese patients. ${ }^{26}$ At the same time, the very obese patients (BMI $>35 \mathrm{~kg} \mathrm{~m}^{-2}$ ) in HF studies do not seem to have favorable survival. ${ }^{18,27}$ Interestingly, we did not find statistically significant differences across the BMI categories with respect to maximal workload oxygen consumption ( $\mathrm{VO}_{2}$ workload). We used $\mathrm{VO}_{2}$ workload in this analysis as a surrogate maker for cardiopulmonary fitness, which has been shown to modify the obesity paradox in HF studies. $^{28}$

Data from the Registry to Evaluate Early and Long-term Pulmonary Arterial Hypertension Disease Management (REVEAL registry) demonstrated that obese patients (BM $\geq 30 \mathrm{~kg}$ $\mathrm{m}^{-2}$ ) had a survival advantage and were more likely to present in functional class III or IV or with greater hemodynamic impairment than non-obese patients. ${ }^{29}$ Our analysis of the relationship of hemodynamic indices and the BMI strata differ considerably from that reported in the REVEAL registry. In this study, the only hemodynamic variable that was statistically different across the BMI strata was the cardiac index, which was notably lower in patients with normal BMI. Overall, there are other remarkable differences between the NIH PH and REVEAL databases that go beyond the eras during which the two registries were conducted. ${ }^{30}$ The REVEAL registry included patients with pulmonary capillary pressures in the ranges of $16-18 \mathrm{~mm} \mathrm{Hg}$. The majority of such patients were older, had more severe hemodynamic impairments and were more likely to be obese than patients with a PCWP $₫ 5 \mathrm{~mm} \mathrm{Hg} .{ }^{31}$ In addition, a considerable number of patients (37\%) in the REVEAL registry had COPD and sleep apnea, ${ }^{32}$ both conditions that met exclusion criteria in NIH PH database.

Our study further extends the observation of obesity paradox among group $1 \mathrm{PH}$ patients, especially with respect to the intriguing curvilinear relationship of BMI and survival. There is a paucity of literature on the relationship between obesity and mortality in $\mathrm{PH}$ patients. Scientific evidence is even sparser on the question of whether the obesity paradox, across the spectrum of the current WHO PH classifications, still remains a valid phenomenon. For instance, interesting evidence has emerged to suggest that the obesity paradox may not be uniformly applicable to all subtypes of HF patients. Along the same lines, a recent study by Shah et al. ${ }^{33}$ demonstrated that the obesity paradox was confined to a subset of older patients, those with lower ejection fraction and those without diabetes mellitus. Furthermore, a study by Zamora et al. ${ }^{34}$ reported that over the long-term follow-up of ischemic and nonischemic HF patients, the obesity paradox was only observed in patients with non-ischemic HF. A study by Kuwat et al., ${ }^{35}$ evaluating patients with idiopathic PAH on vasodilator therapies, failed to show an association between obesity and mortality. On the other hand, Benza et al. ${ }^{36}$ demonstrated the modulating effects of obesity on mortality in patients with PAH treated with subcutaneous treprostinil. These patients were observed to have a statistically significant survival advantage compared with their non-obese counterparts, a finding that was also mirrored by Zafir et al., ${ }^{13}$ when they showed that obesity had salutary effects on mortality in both pre- and postcapillary PH. ${ }^{13}$ The obesity-mortality association was observed in their study despite the disparate PH groups, with fundamentally varied 
pathophysiological processes; our findings differ remarkably from the aforementioned study by Zafir et al. ${ }^{13}$ (who included both pre-and postcapillary $\mathrm{PH}$ ) in that patients in the current study were rigorously evaluated and all secondary causes of $\mathrm{PH}$ were excluded and could therefore be appropriately classified into group $1 \mathrm{PH}$ under the current $\mathrm{PH}$ guidelines.

The biological mechanisms underlying the obesity paradox in many CV conditions have been difficult to examine in experimental studies. However, there are some putative physiological mechanisms that have been proposed to explain the observed association between obesity and CV mortality. For example, obese patients are considered to have greater 'metabolic reserve' and may also stand to benefit more from the protective effects of lipoproteins through the binding of endotoxins. Taken together, such mechanisms have been speculated to lead to a favorable interaction of obesity and mortality in patients with established CVD. ${ }^{37-39}$ A recent study reported that the obesity paradox in a $\mathrm{PH}$ animal model could, in part, be explained by an overexpression of the sympathetic nervous activity that then differentially modulates the pulmonary vascular tone, thereby constraining the ill effects of the severity of $\mathrm{PH}^{40}$ In the same vein, some authors have speculated that ischemic preconditioning, from intermittent exposure of chronic hypoxemia, and increased sympathetic nervous activity, in obesity may paradoxically confer a survival advantage. ${ }^{41}$ Despite the above mechanistic propositions for the obesity paradox, there remains no real consensus on its validity. Some opponents of the obesity paradox contend that it is merely a scientific 'artifact' arguing that the obesity paradox can be explained by variables such as lag time bias (from early presentation of obese patients), overreliance on the BMI metric (which is an imperfect measure of total body adiposity), as well as the clustering of unmeasured confounders associated with the phenotype of obesity. ${ }^{42,43}$ Nonetheless, other studies using percent body fat and waist circumference matrices as measures of adiposity have reported the existence of obesity paradox in CVD ${ }^{8,44-48}$

\section{Limitations}

Among the limitations of this study were that patients in the NIH PH database were somewhat younger compared with more recent $\mathrm{PH}$ registries. ${ }^{30}$ Second, the prognosis and survival outlook of $\mathrm{PH}$ patients during the period of the study was dismal compared with the current era, in part, due to the wide availability of pulmonary vasodilator therapies coupled with widespread information of $\mathrm{PH}$ necessitating early referral. ${ }^{49,50}$ Third, there have been several adaptations of the $\mathrm{PH}$ guidelines including several nomenclatural and classification changes, since the conclusion of the registry. ${ }^{51}$ Fourth, we used BMI as a measure of obesity even though this metric is an imperfect measure of total body adiposity in contrast to other metrics such as percent body fat and waist circumference measurements. ${ }^{52,53}$ Finally, the number of patients in the underweight and obese groups was relatively small (18 and 27, respectively). These limitations are offset by the strengths of the current study, including the rigorous screening for group $1 \mathrm{PH}$, multicenter enrollment, long-term follow-up (5 years) and adjustment for the PHC risk equation, derived in the modern era of pulmonary vasodilator therapies. ${ }^{54}$ 


\section{Conclusions}

We observed that the best survival was in the overweight patients, making this more of an 'overweight paradox' than an 'obesity paradox'. Furthermore, obese and morbidly obese patients were found to have better survival than patients in the normal weight and underweight categories. These findings have important implications for risk stratification and prognosis in group $1 \mathrm{PH}$ patients.

\section{References}

1. Poirier P, Giles TD, Bray GA, Hong Y, Stern JS, Pi-Sunyer FX, et al. Obesity and cardiovascular disease: pathophysiology, evaluation, and effect of weight loss: an update of the 1997 American Heart Association Scientific Statement on Obesity and Heart Disease from the Obesity Committee of the Council on Nutrition, Physical. Circulation. 2006; 113:898-918. [PubMed: 16380542]

2. Berrington de Gonzalez A, Hartge P, Cerhan JR, Flint AJ, Hannan L, MacInnis RJ, et al. Body-mass index and mortality among 1.46 million white adults. N Engl J Med. 2010; 363:2211-2219. [PubMed: 21121834]

3. Hubert HB, Feinleib M, McNamara PM, Castelli WP. Obesity as an independent risk factor for cardiovascular disease: a 26-year follow-up of participants in the Framingham Heart Study. Circulation. 1983; 67:968-977. [PubMed: 6219830]

4. Sajkov D, Cowie RJ, Thornton AT, Espinoza HA, McEvoy RD. Pulmonary hypertension and hypoxemia in obstructive sleep apnea syndrome. Am J Respir Crit Care Med. 1994; 149:416-422. [PubMed: 8306039]

5. Bogaard HJ, Al Husseini A, Farkas L, Farkas D, Gomez-Arroyo J, Abbate A, et al. Severe pulmonary hypertension: The role of metabolic and endocrine disorders. Pulm Circ. 2012; 2:148154. [PubMed: 22837855]

6. Lewis CE, McTigue KM, Burke LE, Poirier P, Eckel RH, Howard BV, et al. Mortality, health outcomes, and body mass index in the overweight range: a science advisory from the American Heart Association. Circulation. 2009; 119:3263-3271. [PubMed: 19506107]

7. Lainscak M, von Haehling S, Doehner W, Anker SD. The obesity paradox in chronic disease: facts and numbers. J Cachexia Sarcopenia Muscle. 2012; 3:1-4. [PubMed: 22450395]

8. Clark AL, Fonarow GC, Horwich TB. Obesity and the obesity paradox in heart failure. Prog Cardiovasc Dis. 2014; 56:409-414. [PubMed: 24438732]

9. Horwich TB, Fonarow GC, Hamilton MA, MacLellan WR, Woo MA, Tillisch JH. The relationship between obesity and mortality in patients with heart failure. J Am Coll Cardiol. 2001; 38:789-795. [PubMed: 11527635]

10. Uretsky S, Messerli FH, Bangalore S, Champion A, Cooper-Dehoff RM, Zhou Q, et al. Obesity paradox in patients with hypertension and coronary artery disease. Am J Med. 2007; 120:863-870. [PubMed: 17904457]

11. Badheka AO, Rathod A, Kizilbash MA, Garg N, Mohamad T, Afonso L, et al. Influence of obesity on outcomes in atrial fibrillation: yet another obesity paradox. Am J Med. 2010; 123:646-651. [PubMed: 20609687]

12. Konigstein M, Havakuk O, Arbel Y, Finkelstein A, Ben-Assa E, Leshem Rubinow E, et al. The obesity paradox in patients undergoing transcatheter aortic valve implantation. Clin Cardiol. 2015; 38:76-81. [PubMed: 25649013]

13. Zafrir B, Adir Y, Shehadeh W, Shteinberg M, Salman N, Amir O. The association between obesity, mortality and filling pressures in pulmonary hypertension patients; the 'obesity paradox'. Respir Med. 2013; 107:139-146. [PubMed: 23199841]

14. Hu E-C, He J-G, Liu Z-H, Ni X-H, Zheng Y-G, Gu Q, et al. Survival advantages of excess body mass index in patients with idiopathic pulmonary arterial hypertension. Acta Cardiol. 2014; 69:673-678. [PubMed: 25643438]

15. Greenberg JA. The obesity paradox in the US population. Am J Clin Nutr. 2013; 97:1195-1200. [PubMed: 23636238] 
16. Oreopoulos A, Padwal R, Kalantar-Zadeh K, Fonarow GC, Norris CM, McAlister FA. Body mass index and mortality in heart failure: a meta-analysis. Am Heart J. 2008; 156:13-22. [PubMed: 18585492]

17. Lavie CJ, Mehra MR, Milani RV. Obesity and heart failure prognosis: paradox or reverse epidemiology? Eur Heart J. 2005; 26:5-7. [PubMed: 15615792]

18. Habbu A, Lakkis NM, Dokainish H. The obesity paradox: fact or fiction? Am J Cardiol. 2006; 98:944-948. [PubMed: 16996880]

19. Lavie CJ, De Schutter A, Patel DA, Milani RV. Body composition and fitness in the obesity paradox—body mass index alone does not tell the whole story. Prev Med (Baltim). 2013; 57:1-2.

20. D’Alonzo GE, Barst RJ, Ayres SM, Bergofsky EH, Brundage BH, Detre KM, et al. Survival in patients with primary pulmonary hypertension. Results from a national prospective registry. Ann Intern Med. 1991; 115:343-349. [PubMed: 1863023]

21. Pencina MJ, D’Agostino RBS, Larson MG, Massaro JM, Vasan RS. Predicting the 30-year risk of cardiovascular disease: the framingham heart study. Circulation. 2009; 119:3078-3084. [PubMed: 19506114]

22. Xavier Pi-Sunyer F, Becker DM, Claude B, Carleton RA, Colditz GA, Dietz WH. Executive summary of the clinical guidelines on the identification, evaluation, and treatment of overweight and obesity in adults. Arch Intern Med. 1998; 158:1855-1867. [PubMed: 9759681]

23. Davos CH, Doehner W, Rauchhaus M, Cicoira M, Francis DP, Coats AJS, et al. Body mass and survival in patients with chronic heart failure without cachexia: the importance of obesity. J Card Fail. 2003; 9:29-35. [PubMed: 12612870]

24. Sharma A, Lavie CJ, Borer JS, Vallakati A, Goel S, Lopez-Jimenez F, et al. Meta-analysis of the relation of body mass index to all-cause and cardiovascular mortality and hospitalization in patients with chronic heart failure. Am J Cardiol. 2015; 115:1428-1434. [PubMed: 25772740]

25. Curtis JP, Selter JG, Wang Y, Rathore SS, Jovin IS, Jadbabaie F, et al. The obesity paradox: body mass index and outcomes in patients with heart failure. Arch Intern Med. 2005; 165:55-61. [PubMed: 15642875]

26. Kanwar A, Singh M, Lennon R, Ghanta K, McNallan SM, Roger VL. Frailty and health-related quality of life among residents of long-term care facilities. J Aging Health. 2013; 25:792-802. [PubMed: 23801154]

27. Nagarajan V, Cauthen CA, Starling RC, Tang WHW. Prognosis of morbid obesity patients with advanced heart failure. Congest Heart Fail. 2013; 19:160-164. [PubMed: 23910700]

28. Clark AL, Fonarow GC, Horwich TB. Impact of cardiorespiratory fitness on the obesity paradox in patients with systolic heart failure. Am J Cardiol. 2015; 115:209-213. [PubMed: 25465933]

29. Burger CD, Foreman AJ, Miller DP, Safford RE, McGoon MD, Badesch DB. Comparison of body habitus in patients with pulmonary arterial hypertension enrolled in the Registry to Evaluate Early and Long-term PAH Disease Management with normative values from the National Health and Nutrition Examination. Survey Mayo Clin Proc. 2011; 86:105-112. [PubMed: 21282484]

30. McGoon MD, Benza RL, Escribano-Subias P, Jiang X, Miller DP, Peacock AJ, et al. Pulmonary arterial hypertension: epidemiology and registries. J Am Coll Cardiol. 2013; 62:D51-D59. [PubMed: 24355642]

31. Frost AE, Farber HW, Barst RJ, Miller DP, Elliott CG, McGoon MD. Demographics and outcomes of patients diagnosed with pulmonary hypertension with pulmonary capillary wedge pressures 16 to $18 \mathrm{~mm} \mathrm{Hg}$ : insights from the REVEAL Registry. Chest. 2013; 143:185-195. [PubMed: 22661451]

32. Poms AD, Turner M, Farber HW, Meltzer LA, McGoon MD. Comorbid conditions and outcomes in patients with pulmonary arterial hypertension: a REVEAL registry analysis. Chest. 2013; 144:169-176. [PubMed: 23348820]

33. Shah R, Gayat E, Januzzi JLJ, Sato N, Cohen-Solal A, diSomma S, et al. Body mass index and mortality in acutely decompensated heart failure across the world: a global obesity paradox. J Am Coll Cardiol. 2014; 63:778-785. [PubMed: 24315906]

34. Zamora E, Lupon J, de Antonio M, Urrutia A, Coll R, Diez C, et al. The obesity paradox in heart failure: is etiology a key factor? Int J Cardiol. 2013; 166:601-605. [PubMed: 22204855] 
35. Kawut SM, Horn EM, Berekashvili KK, Garofano RP, Goldsmith RL, Widlitz AC, et al. New predictors of outcome in idiopathic pulmonary arterial hypertension. Am J Cardiol. 2005; 95:199203. [PubMed: 15642552]

36. Benza RL, Gomberg-Maitland M, Naeije R, Arneson CP, Lang IM. Prognostic factors associated with increased survival in patients with pulmonary arterial hypertension treated with subcutaneous treprostinil in randomized, placebo-controlled trials. J Heart Lung Transplant. 2011; 30:982-989. [PubMed: 21531577]

37. Lavie CJ, De Schutter A, Parto P, Jahangir E, Kokkinos P, Ortega FB, et al. Obesity and prevalence of cardiovascular diseases and prognosis - the obesity paradox updated. Prog Cardiovasc Dis. 2016; 58:537-547. [PubMed: 26826295]

38. Lavie CJ, Sharma A, Alpert MA, De Schutter A, Lopez-Jimenez F, Milani RV, et al. Update on obesity and obesity paradox in heart failure. Prog Cardiovasc Dis. 2016; 58:393-400. [PubMed: 26721180]

39. Rauchhaus M, Coats AJ, Anker SD. The endotoxin-ipoprotein hypothesis. Lancet (London, England). 2000; 356:930-933.

40. Diong C, Jones PP, Tsuchimochi H, Gray EA, Hughes G, Inagaki T, et al. Sympathetic hyperexcitation in obesity and pulmonary hypertension: physiological relevance to the 'obesity paradox'. Int J Obes (Lond). 2016; 40:938-946. [PubMed: 27001546]

41. Ozeke O, Ozer C, Gungor M, Celenk MK, Dincer H, Ilicin G. Chronic intermittent hypoxia caused by obstructive sleep apnea may play an important role in explaining the morbidity-mortality paradox of obesity. Med Hypotheses. 2011; 76:61-63. [PubMed: 20822856]

42. Gielen S, Sandri M. The obesity paradox—a scientific artifact? Int J Cardiol. 2013; 162:140-142. [PubMed: 22385729]

43. Lavie CJ, McAuley PA, Church TS, Milani RV, Blair SN. Obesity and cardiovascular diseases: implications regarding fitness, fatness, and severity in the obesity paradox. J Am Coll Cardiol. 2014; 63:1345-1354. [PubMed: 24530666]

44. Lavie CJ, Osman AF, Milani RV, Mehra MR. Body composition and prognosis in chronic systolic heart failure: the obesity paradox. Am J Cardiol. 2003; 91:891-894. [PubMed: 12667583]

45. De Schutter A, Lavie CJ, Milani RV. The impact of obesity on risk factors and prevalence and prognosis of coronary heart disease-the obesity paradox. Prog Cardiovasc Dis. 2014; 56:401-408. [PubMed: 24438731]

46. Lavie CJ, De Schutter A, Patel DA, Romero-Corral A, Artham SM, Milani RV. Body composition and survival in stable coronary heart disease: impact of lean mass index and body fat in the 'obesity paradox'. J Am Coll Cardiol. 2012; 60:1374-1380. [PubMed: 22958953]

47. Clark AL, Chyu J, Horwich TB. The obesity paradox in men versus women with systolic heart failure. Am J Cardiol. 2012; 110:77-82. [PubMed: 22497678]

48. Lavie CJ, De Schutter A, Patel D, Artham SM, Milani RV. Body composition and coronary heart disease mortality-an obesity or a lean paradox? Mayo Clin Proc. 2011; 86:857-864. [PubMed: 21878597]

49. Galie N, Palazzini M, Manes A. Pulmonary arterial hypertension: from the kingdom of the neardead to multiple clinical trial meta-analyses. Eur Heart J. 2010; 31:2080-2086. [PubMed: 20504865]

50. Deano RC, Glassner-Kolmin C, Rubenfire M, Frost A, Visovatti S, McLaughlin VV, et al. Referral of patients with pulmonary hypertension diagnoses to tertiary pulmonary hypertension centers: the multicenter RePHerral study. JAMA Intern Med. 2013; 173:887-893. [PubMed: 23568223]

51. Simonneau G, Gatzoulis MA, Adatia I, Celermajer D, Denton C, Ghofrani A, et al. Updated clinical classification of pulmonary hypertension. J Am Coll Cardiol. 2013; 62:D34-D41. [PubMed: 24355639]

52. Cepeda-Valery B, Pressman GS, Figueredo VM, Romero-Corral A. Impact of obesity on total and cardiovascular mortality—fat or fiction? Nat Rev Cardiol. 2011; 8:233-237. [PubMed: 21263454]

53. Coutinho T, Goel K, Correa de Sa D, Kragelund C, Kanaya AM, Zeller M, et al. Central obesity and survival in subjects with coronary artery disease: a systematic review of the literature and collaborative analysis with individual subject data. J Am Coll Cardiol. 2011; 57:1877-1886. [PubMed: 21545944] 
54. Thenappan T, Shah SJ, Rich S, Tian L, Archer SL, Gomberg-Maitland M. Survival in pulmonary arterial hypertension: a reappraisal of the NIH risk stratification equation. Eur Respir J. 2010; 35:1079-1087. [PubMed: 20032020] 


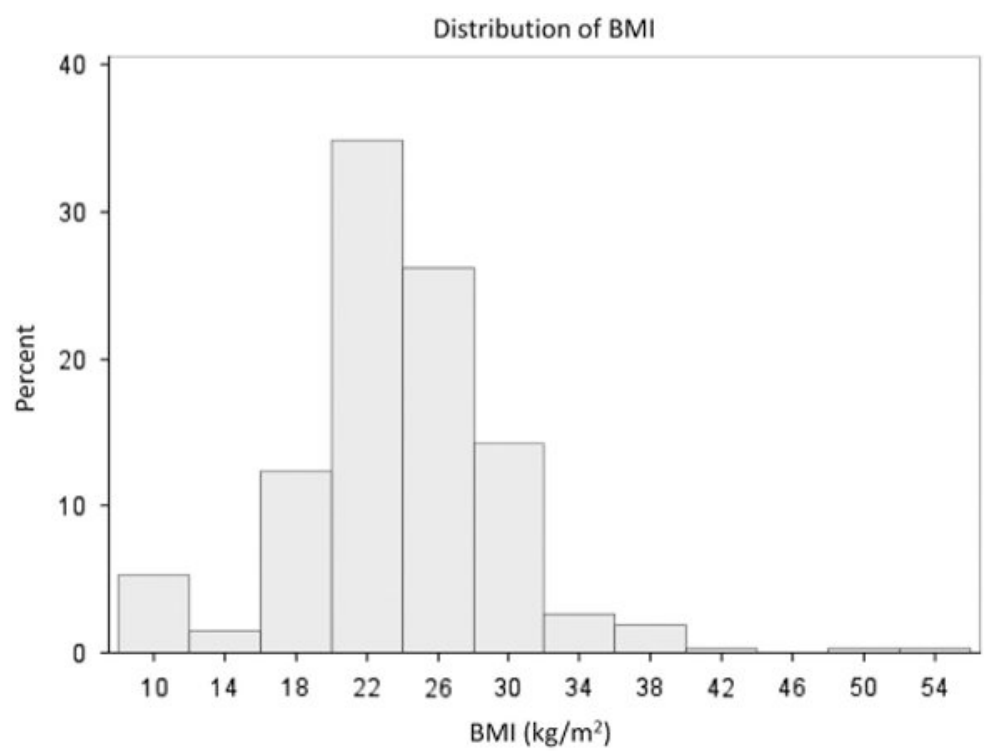

Figure 1.

Histogram of BMI distribution. The histogram showing the distribution of the BMI is shown. Most of the patients with primary $\mathrm{PH}$ in this study. 
a $_{70}$

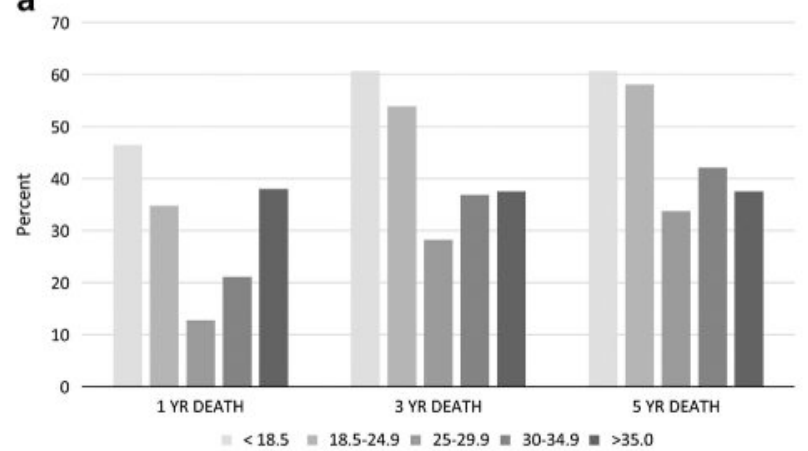

b

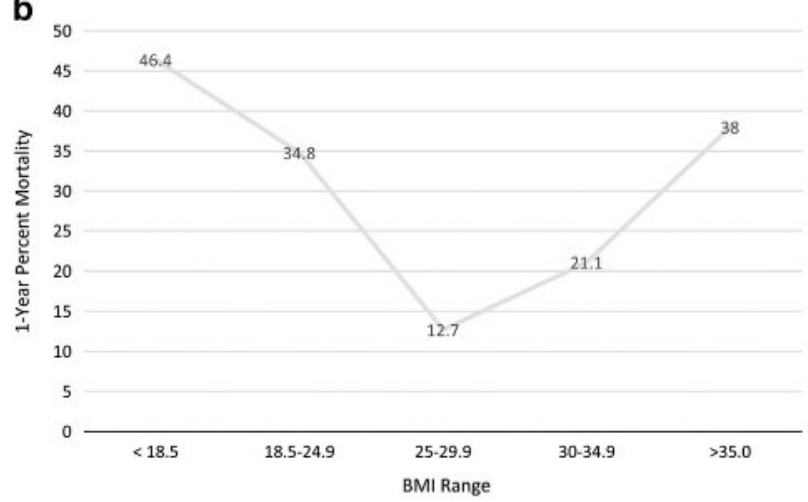

Figure 2.

BMI and survival. As shown in (a), the best survival at all time points is in the verweight group, and survival improves with increasing BMI, particularly at the late time point. In (b), the U-shaped relationship between BMI and survival is apparent. 


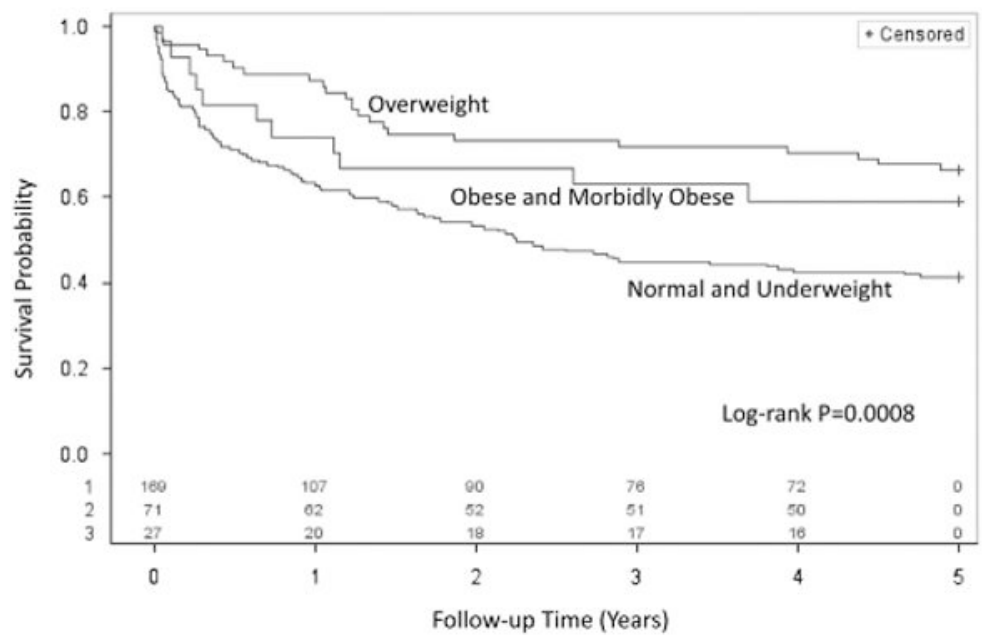

Figure 3.

Kaplan-Meier survival curves for body mass index categories. Kaplan-Meier curves are shown for patients with the five BMI categories showing incremental survival benefit with increasing BMI quartiles (log-rank $P=0.008)$. 


\section{西}

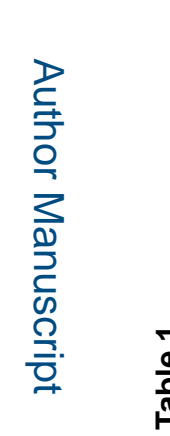

로을

Int J Obes (Lond). Author manuscript; available in PMC 2017 August 09. 